\title{
Neuroactive Steroids are Altered in Schizophrenia and Bipolar Disorder: Relevance to Pathophysiology and Therapeutics
}

\author{
Christine E Marx ${ }^{*}, 1,2$, Robert D Stevens ${ }^{3}$, Lawrence J Shampine ${ }^{1,2}$, Veska Uzunova ${ }^{4}$, William T Trost ${ }^{1,2}$, \\ Marian I Butterfield ',2, Mark W Massing, ${ }^{2}$, Robert M Hamer, A Leslie Morrow ${ }^{5,6}$ and Jeffrey A Lieberman ${ }^{7}$ \\ 'Department of Psychiatry and Behavioral Sciences, Duke University Medical Center, Durham, NC, USA; ${ }^{2}$ Department of Veterans Affairs \\ Medical Center, Durham, NC, USA; ${ }^{3}$ Sarah W. Stedman Nutrition and Metabolism Center, Duke University Medical Center, Durham, NC, USA; \\ ${ }^{4}$ Neuroscience Research, Novartis Institutes for BioMedical Research, Novartis Pharma AG, Basel, Switzerland; ${ }^{5}$ Department of Psychiatry, \\ University of North Carolina at Chapel Hill, Chapel Hill, NC, USA; ${ }^{6}$ Department of Pharmacology, University of North Carolina at Chapel Hill, \\ Chapel Hill, NC, USA; ' Department of Psychiatry, Columbia University College of Physicians and Surgeons, New York, NY, USA
}

\begin{abstract}
Evidence suggests that neuroactive steroids may be candidate modulators of schizophrenia pathophysiology and therapeutics. We therefore investigated neuroactive steroid levels in post-mortem brain tissue from subjects with schizophrenia, bipolar disorder, nonpsychotic depression, and control subjects to determine if neuroactive steroids are altered in these disorders. Posterior cingulate and parietal cortex tissue from the Stanley Foundation Neuropathology Consortium collection was analyzed for neuroactive steroids by negative ion chemical ionization gas chromatography/mass spectrometry preceded by high-performance liquid chromatography. Subjects with schizophrenia, bipolar disorder, nonpsychotic depression, and control subjects were group matched for age, sex, ethnicity, brain pH, and post-mortem interval ( $n=14-15$ per group, 59-60 subjects total). Statistical analyses were performed by ANOVA with post-hoc Dunnett tests on log transformed neuroactive steroid levels. Pregnenolone and allopregnanolone were present in human post-mortem brain tissue at considerably higher concentrations than typically observed in serum or plasma. Pregnenolone and dehydroepiandrosterone levels were higher in subjects with schizophrenia and bipolar disorder compared to control subjects in both posterior cingulate and parietal cortex. Allopregnanolone levels tended to be decreased in parietal cortex in subjects with schizophrenia compared to control subjects. Neuroactive steroids are present in human post-mortem brain tissue at physiologically relevant concentrations and altered in subjects with schizophrenia and bipolar disorder. A number of neuroactive steroids act at inhibitory GABA $A_{A}$ and excitatory NMDA receptors and demonstrate neuroprotective and neurotrophic effects. Neuroactive steroids may therefore be candidate modulators of the pathophysiology of schizophrenia and bipolar disorder, and relevant to the treatment of these disorders.

Neuropsychopharmacology (2006) 3 I, 1249-1263. doi: I 0. I 038/sj.npp. I 300952; published online 23 November 2005
\end{abstract}

Keywords: schizophrenia; bipolar disorder; neuroactive steroid; post-mortem; pregnenolone; DHEA

\section{BACKGROUND}

Neuroactive steroids can be synthesized de novo in the brain from cholesterol (neurosteroids) or in the periphery by the adrenals and gonads (Paul and Purdy, 1992). Neuroactive steroids rapidly alter neuronal excitability by

Previous presentations: American College of Neuropsychopharmacology (ACNP) Annual Meeting, San Juan, Puerto Rico, December I4, 2004; The International Congress on Schizophrenia Research, Savannah GA, April 5, 2005.

*Correspondence: Dr CE Marx, Department of Psychiatry and Behavioral Sciences, Duke University Medical Center and Durham VA Medical Center, 508 Fulton Street, MHSL II6A, Durham, NC 27705, USA, Tel: + I 91928604 I I ext 7426, Fax: + I 91928668 I I, E-mail:marx000I@mc.duke.edu

Received 25 March 2005; revised 14 September 2005; accepted 21 September 2005

Online publication: 28 September 2005 at http://www.acnp.org/ citations/Npp092805050205/default.pdf acting at inhibitory $\mathrm{GABA}_{\mathrm{A}}$ and/or excitatory NMDA receptors, among others (Rupprecht and Holsboer, 1999, review). For example, the neuroactive steroid $3 \alpha$-hydroxy$5 \alpha$-pregnan-20-one (allopregnanolone) potentiates $\mathrm{GABA}_{\mathrm{A}}$ receptor response with greater potency than benzodiazepines or barbiturates (Majewska et al, 1986; Morrow et al, 1987, 1990). Certain neuroactive steroids also demonstrate activity at nicotinic acetylcholine (Mayo et al, 2003; Darnaudery et al, 1998, 2002; Pallares et al, 1998; Rhodes et al, 1996, 1997) and $\sigma_{1}\left(\right.$ sigma $\left._{1}\right)$ receptors (Maurice et al, 2001). Pregnenolone sulfate and dehydroepiandrosterone (DHEA) are positive modulators of NMDA receptors (Irwin et al, 1994; Wu et al, 1991; Compagnone and Mellon, 1998; Debonnel et al, 1996; Bergeron et al, 1996) and negative modulators of $\mathrm{GABA}_{\mathrm{A}}$ receptors (Majewska et al, 1988, 1990; Imamura and Prasad, 1998; Park-Chung et al, 1999). Many of these endogenous molecules are present at physiologically relevant concentrations in both male and female rodent brain, but little is currently known regarding 
their regulation in the human central nervous system. Available data suggest that neuroactive steroids are also present in human brain, but few investigations have been conducted to date. Several small post-mortem studies have used radioimmunoassay approaches (Lacroix et al, 1987; Lanthier and Patwardhan, 1986; Bixo et al, 1997; Brown et al, 2003). Two studies to our knowledge have utilized mass spectrometry-based techniques to determine neuroactive steroid levels in human post-mortem brain tissue from subjects with Alzheimer's disease (Weill-Engerer et al, 2002, 2003), the most highly sensitive and specific current methodology (Purdy et al, in press). It is currently unknown if neuroactive steroid levels are altered in post-mortem brain tissue from subjects with schizophrenia, bipolar disorder, or depression. Since converging evidence suggests that neuroactive steroids may be candidate modulators of the pathophysiology and therapeutics of these disorders, we determined levels of these endogenous molecules in postmortem brain tissue from the Stanley Neuropathology Consortium.

Neuroactive steroids are lipophilic and cross the bloodbrain barrier readily in their unsulfated forms. In addition to neuroactive steroids formed in the brain from cholesterol or other precursors, it is likely that peripheral neuroactive steroids enter the brain and contribute to central nervous system neuroactive steroid levels, as has been demonstrated in rodents (Marx et al, 2003; Wang et al, 1997; Karavolas et al, 1979; Raisinghani et al, 1968). The precise dynamics of neuroactive steroid compartmentalization have been very challenging to determine (Baulieu et al, 2001). Rodent evidence suggests that brain neuroactive steroid levels are generally higher than plasma or serum levels, achieving central nervous system concentrations known to modulate inhibitory $\mathrm{GABA}_{\mathrm{A}}$ (Morrow et al, 1987, 1990) and excitatory NMDA (Compagnone and Mellon, 1998; Akwa et al, 2001) receptor actions, and to influence GABA release (Mtchedlishvili and Kapur, 2003) and glutamate release (Meyer et al, 2002). Nanomolar concentrations of allopregnanolone modulate $\mathrm{GABA}_{\mathrm{A}}$ receptors (Morrow et al, 1987, 1990; Gee et al, 1988; Puia et al, 1990; Shu et al, 2004) and clearly demonstrate behavioral effects at physiologically relevant concentrations. Micromolar concentrations of pregnenolone sulfate, DHEA, and DHEAS modulate $\mathrm{GABA}_{\mathrm{A}}$ (Majewska et al, 1988, 1990; Imamura and Prasad, 1998; Park-Chung et al, 1999) and NMDA (Irwin et al, 1994; $\mathrm{Wu}$ et al, 1991; Bowlby, 1993) receptors. In addition, nanomolar levels of pregnenolone sulfate, consistent with levels found in rodent hippocampus (Kimoto et al, 2001), decrease GABA release from hippocampal neurons (Mtchedlishvili and Kapur, 2003), and DHEAS (100 nM) may increase glutamate release (Meyer et al, 2002). A number of neuroactive steroids therefore exhibit the capacity to modulate the major excitatory and inhibitory neurotransmitter systems in the mammalian brain. It is thus important to characterize neuroactive steroid levels in human brain, since alterations in glutamatergic and GABAergic neurotransmitter systems have been implicated in a number of psychiatric disorders including schizophrenia and bipolar disorder.

An expanding literature in animal models documents additional neuroactive steroid properties that may be relevant to the pathophysiology and therapeutics of psychiatric disorders. For example, both clozapine (Marx et al, 2003; Barbaccia et al, 2001) and olanzapine (Marx et al, 2000a, 2003) dose dependently elevate the neuroactive steroid allopregnanolone in rodent brain, and we have hypothesized that neuroactive steroid induction may contribute the therapeutic efficacy of these compounds (Marx et al, 2003, 2005). Furthermore, recent data support the possibility that allopregnanolone potentiates olanzapine actions on dopamine-mediated behaviors in rodents (Ugale et al, 2004). In addition to certain antipsychotics, fluoxetine also elevates allopregnanolone levels in animal models (Uzunov et al, 1996; Pinna et al, 2003, 2004), and these increases have been linked to its antidepressant-like effects in rodent behavioral models (Khisti and Chopde, 2000a; Khisti et al, 2000b) and to the mitigation of aggression in socially isolated rats (Pinna et al, 2003). We have also determined that olanzapine and fluoxetine elevate pregnenolone levels in rodent hippocampus (Trost et al, 2005). Since pregnenolone (Flood et al, 1992) and pregnenolone sulfate (Flood et al, 1992, 1995; Vallee et al, 1997, 2003; Akwa et al, 2001) enhance learning and memory in rodents, and since low pregnenolone levels have been associated with depressive symptoms in humans (George et al, 1994), pregnenolone elevations may be relevant to cognitive deficits in schizophrenia, and could potentially contribute to olanzapine and fluoxetine effects on depressive symptoms, including decreased concentration. Although data in humans are limited, it has also been demonstrated that fluoxetine- and fluvoxamine-induced elevations in cerebrospinal fluid allopregnanolone levels are correlated with symptom improvement in patients with depression (Uzunova et al, 1998). Initial evidence therefore suggests that neuroactive steroid alterations may contribute to the therapeutic effects of antipsychotics and selective serotonin reuptake inhibitors.

In addition to alterations in neuroactive steroid levels following certain antipsychotic and antidepressant agents, an extensive literature documents the neuroprotective and neurotrophic properties of a number of neuroactive steroids, and these actions may be relevant to the pathophysiology of schizophrenia and other psychiatric disorders. For example, DHEA and DHEAS decrease neuronal death following anoxia (Marx et al, 2000b), and obstetrical complications resulting in hypoxia are associated with increased schizophrenia risk (Dalman et al, 2001; Cannon et al, 1999, 2000; Geddes et al, 1999). Allopregnanolone demonstrates anticonvulsant actions in a number of seizure paradigms (Kokate et al, 1994, 1996; Devaud et al, 1995; Belelli et al, 1989) and exhibits pronounced protective effects against neurodegeneration in a mouse model of Niemann-Pick type $C$ disease (Griffin et al, 2004). DHEA and DHEAS increase axonal and dendritic outgrowth, respectively (Compagnone and Mellon, 1998), and DHEA increases neurogenesis in rodent hippocampal dentate gyrus (Karishma and Herbert, 2002) and human neural stem cells (Suzuki et al, 2004). Pregnenolone sulfate may also increase neurogenesis in rodent hippocampus (Mayo et al, 2005), although results are conflicting (Wang et al, 2005). Allopregnanolone increases proliferation in rodent and human neural progenitor cells (Wang et al, 2005). Neuroactive steroids therefore appear to impact neuroplasticity, a possibility that 
has critical ramifications for neuronal function. In addition, neuroactive steroids appear to be regulated differently in males and females (Bjornerem et al, 2004; Laughlin and Barrett-Connor, 2000; Genazzani et al, 1998; Pearson Murphy and Allison, 2000), and may therefore modulate the neurobiology of sex differences in a number of psychiatric disorders. Finally, augmentation with the neuroactive steroid DHEA decreases negative symptoms, anxiety, and depressive symptoms in patients with schizophrenia (Strous et al, 2003), suggesting a potential role for neuroactive steroids in schizophrenia therapeutics.

Since converging evidence suggests that neuroactive steroids may be candidate modulators of schizophrenia pathophysiology and treatment strategies, we investigated these molecules in subjects with schizophrenia, bipolar disorder, nonpsychotic depression, and control subjects in two brain regions, posterior cingulate and parietal cortex.

\section{METHODS}

Posterior cingulate and parietal cortex post-mortem brain tissue was generously provided by the Stanley Neuropathology Consortium. A number of brain regions including posterior cingulate (Haznedar et al, 2004) and parietal cortex (Danckert et al, 2004) have been linked to schizophrenia pathophysiology; however, tissue availability within the Stanley Neuropathology Consortium ultimately dictated the two brain regions to be tested. Characteristics of this post-mortem tissue collection have been published previously (Torrey et al, 2000, 2005; Knable et al, 2004; Jarskog et $a l, 2000)$. Briefly, subjects were group matched for age, sex, ethnicity, brain $\mathrm{pH}$, and post-mortem interval. For each brain region, frozen tissue from 15 subjects each with schizophrenia and bipolar disorder, 14-15 subjects with nonpsychotic depression, and 15 nonpsychiatric control subjects was analyzed for neuroactive steroids. The posterior cingulate collection was missing tissue from one subject with depression, and therefore 14 specimens from this group were analyzed. Neuroactive steroid analyses for both posterior cingulate and parietal cortex were performed in a manner blind to group condition.

Neuroactive steroid analyses were performed by highly sensitive and specific gas chromatography/mass spectrometry (GC/MS) preceded by high-performance liquid chromatography (HPLC) purification as previously described (Uzunova et al, 1998; Dong et al, 2001), with several modifications. All glasssware was silanized. Brain tissue was homogenized in five volumes of distilled water containing a trace amount of tritiated neuroactive steroid $(4000 \mathrm{dpm} /$ injection, New England Nuclear) to detect the HPLC fraction of interest, as well as a constant amount of deuterated allopregnanolone (D4-allopregnanolone) and deuterated pregnenolone (D4-pregnenolone) as the internal standards. Supernatants were extracted three times with three volumes of ethyl acetate and dried under nitrogen prior to HPLC. HPLC purification was performed with $900 \mu \mathrm{l}$ injections per sample on an 1100 Series Agilent HPLC equipped with a Packard 500TR Flow Scintillation Analyzer for radiopeak detection. Each steroid was collected into a separate fraction based upon the retention time of its radioactive analogue, utilizing hexane, tetrahydrofuran, and ethanol in the mobile phase and a Phenomenex LiChrosorb DIOL $(5 \mu \mathrm{m}$ particle size) $250 \mathrm{~mm} \times 4.6 \mathrm{~mm}$ column; flow rate $1.0 \mathrm{ml} / \mathrm{min}$.

Samples were then transferred to $1 \mathrm{ml}$ Reacti-Vials, evaporated to dryness, and derivatized utilizing heptafluorobutyric acid anhydride (HFBA) $(50 \mu \mathrm{l}$ HFBA added to $450 \mu \mathrm{l}$ ethyl acetate at room temperature for $2 \mathrm{~h}$ ). Derivatized samples were transferred to autosampler vials equipped with deactivated glass inserts. Standards and samples were injected onto an Agilent 5973 Mass Spectrometer (MS) coupled to an Agilent $6890 \mathrm{~N}$ Gas Chromatograph (GC) equipped with an Agilent HP-5MS 30 meter $\times 0.250 \mathrm{~mm} \times 0.25 \mu \mathrm{m}$ capillary column, and analyzed in the negative ion chemical ionization mode (NICI) utilizing methane as the reaction gas and helium as the carrier gas. Each sample was injected in duplicate. The derivatized steroids of interest subjected to NICI yield negative ions in the mass range between $\mathrm{m} / z 100$ and $\mathrm{m} / \mathrm{z}$ 700. In addition to the GC retention time characteristic of each steroid, the structural identification of each neuroactive steroid assayed was provided by its unique mass fragmentation pattern. Mass spectrometer single ion monitoring mode was utilized to focus on the most abundant ion fragment for each HFBA steroid derivative (pregnenolone 492.3, 472.4; DHEA 464.4, 444.4; allopregnanolone 474.4, 494.3).

For neuroactive steroid quantification, the standard curve for the steroid of interest was prepared by combining varying known quantities of steroids (Steraloids) with a constant amount of deuterated internal standard. Identical to the experimental samples, each standard curve sample was extracted three times in ethyl acetate prior to HPLC purification and GC/MS injection; standard curve $r^{2}=0.99$ for each neuroactive steroid. The area under the peak of a known quantity of each steroid was divided by the area under the peak of the internal standard. This ratio was then plotted on the $y$-axis against known quantities of each steroid to generate the standard curve. Only peaks with a signal to noise ratio greater or equal to $5: 1$ were integrated. The limit of neuroactive steroid detection with this method was $2 \mathrm{pg}$ for DHEA and allopregnanolone, and $10 \mathrm{pg}$ for pregnenolone. The intra-assay coefficients of variation were $3.9 \%$ for pregnenolone, $2.1 \%$ for DHEA, and $6.6 \%$ for allopregnanolone.

\section{Statistical Analyses Methods}

Primary analyses. Neuroactive steroid levels were log transformed due to the skewness of the distributions and the relationship of the mean and SD. We calculated means and standard deviations for all transformed neuroactive steroid levels. For each neuroactive steroid level (pregnenolone, DHEA, allopregnanolone), we performed a oneway, four-group analysis of variance (ANOVA) with posthoc Dunnett tests comparing each of the diagnostic group means with the mean of the control group (no psychiatric diagnosis) in each brain region: (1) posterior cingulate and (2) parietal cortex.

Secondary analyses. Three secondary analyses were performed subsequent to the initial primary analyses above: (1) We performed separate one-way, four-group ANOVAs on 
log-transformed neuroactive steroid levels with post hoc Dunnett tests for males and females as exploratory secondary analyses. Since the existing literature suggests that neuroactive steroids may be regulated differently in males and females, separate analyses stratified by sex were judged to be the most appropriate statistical approach to begin to address the question of possible sex differences in neuroactive steroid levels in human brain. Since we recognize that separating the sample into male and female groups may greatly reduce statistical power, we regard these secondary analyses as preliminary investigations for future hypothesis testing in a larger cohort of subjects. (2) Given rodent evidence suggesting that clozapine and olanzapine elevate the neuroactive steroid allopregnanolone in rodent brain but that haloperidol and risperidone do not demonstrate this effect (Marx et al, 2003; Barbaccia et al, 2001), we performed a Mann-Whitney $U$ statistic comparing neuroactive steroid levels in patients with schizophrenia or bipolar disorder receiving clozapine at the time of death $(n=7)$ with neuroactive steroid levels in patients receiving a typical antipsychotic, risperidone, or no antipsychotic at this time point $(n=23)$. No patients were receiving olanzapine at the time of death. (3) Finally, we investigated if neuroactive steroids were associated with lifetime antipsychotic exposure (in fluphenazine equivalents) by determining the Pearson's correlation coefficient for each neuroactive steroid and this variable.

\section{RESULTS}

\section{Overview: Selected Neuroactive Steroid Biosynthetic Pathways}

Both DHEA and allopregnanolone are downstream metabolites of the precursor steroid pregnenolone (Figure 1). In addition to metabolism to DHEA and allopregnanolone, pregnenolone can be metabolized to a number of other neuroactive steroids. Figure 1 represents a partial listing of steroid metabolites and the enzymes involved in each biosynthetic step.

\section{Primary Analyses}

Neuroactive steroids in posterior cingulate. Pregnenolone, DHEA, and allopregnanolone are present in posterior cingulate at physiologically relevant nanomolar concentrations, Table 1. Median pregnenolone and allopregnanolone levels in posterior cingulate exceed typical serum or plasma concentrations observed in males, follicular-phase females, and postmenopausal females by approximately 10 -fold or greater in all subject groups. Median DHEA levels in posterior cingulate are comparable to typical serum and plasma levels, Table 1. Pregnenolone levels and DHEA levels (log transformed) are significantly elevated in posterior cingulate tissue from subjects with schizophrenia and bipolar disorder compared to control subjects; allopregnanolone levels (log transformed) are not significantly altered in posterior cingulate tissue from subjects with a psychiatric diagnosis compared to control subjects, Figure 2.

Neuroactive steroids in parietal cortex. Similar to posterior cingulate, pregnenolone and allopregnanolone levels in parietal cortex exceed typical serum or plasma levels observed in males, follicular-phase females, and postmenopausal females by approximately 10 -fold or greater in each subject group; median DHEA levels in parietal cortex are comparable to typical serum and plasma levels, Table 2. Also similar to posterior cingulate, pregnenolone and DHEA levels (log transformed) are significantly elevated in parietal cortex tissue from subjects with bipolar disorder compared to control subjects; pregnenolone and DHEA levels (log transformed) also tended to be higher in the

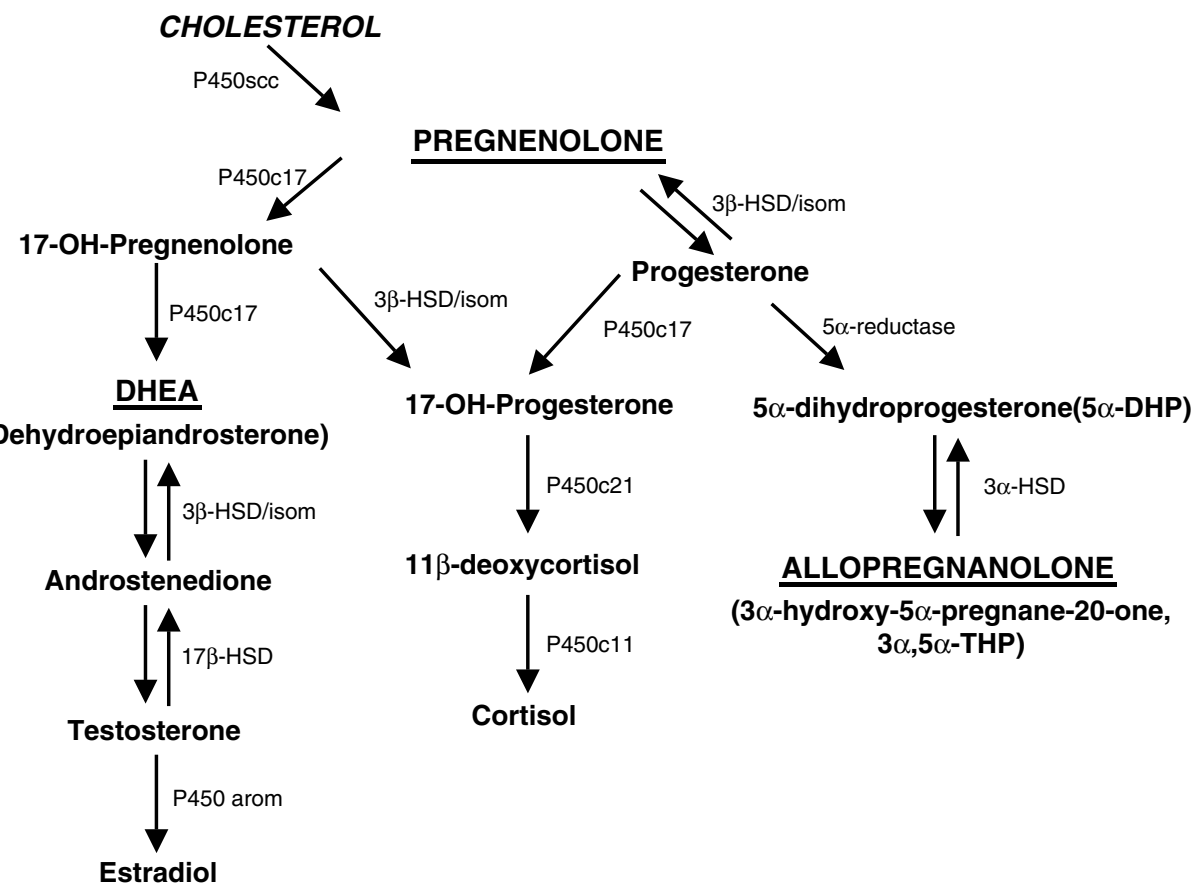

Figure I Partial listing of selected biosynthetic pathways. 
Table I Neuroactive Steroid Levels (ng/g) in Posterior Cingulate

\begin{tabular}{lrrrrrr}
\hline & N & Min & Q1 & Med & Q3 & Max \\
\hline $\begin{array}{llrrrr}\text { Pregnenolone } \\
\quad \text { Control }\end{array}$ & 15 & 3.14 & 6.05 & 9.32 & 13.50 & 46.06 \\
Schizophrenia & 15 & 2.89 & 14.31 & 22.27 & 34.69 & 107.87 \\
Bipolar & 15 & 8.50 & 12.21 & 31.00 & 50.65 & 163.62 \\
Depression & 14 & 6.34 & 8.75 & 14.77 & 19.35 & 186.22
\end{tabular}

DHEA

$\begin{array}{lrrrrrr}\text { Control } & 15 & 1.24 & 1.63 & 5.68 & 10.07 & 24.58 \\ \text { Schizophrenia } & 15 & 2.21 & 7.54 & 13.38 & 18.80 & 44.22 \\ \text { Bipolar } & 15 & 3.32 & 8.15 & 16.35 & 26.50 & 41.71 \\ \text { Depression } & 14 & 1.82 & 3.22 & 7.64 & 13.68 & 27.28\end{array}$

Allopregnanolone

$\begin{array}{lrrrrrr}\text { Control } & 15 & 1.68 & 5.20 & 6.77 & 10.32 & 54.98 \\ \text { Schizophrenia } & 15 & 1.90 & 4.64 & 6.56 & 9.56 & 30.58 \\ \text { Bipolar } & 15 & 2.82 & 5.27 & 8.12 & 21.77 & 64.23 \\ \text { Depression } & 14 & 1.89 & 4.02 & 12.42 & 15.50 & 70.33\end{array}$

$N=$ number of subjects; $M i n=$ minimum value in group; $\mathrm{Q}$ I = lower quartile; Med=median; $\mathrm{Q} 3=$ upper quartile; $M a x=$ maximum value in group.

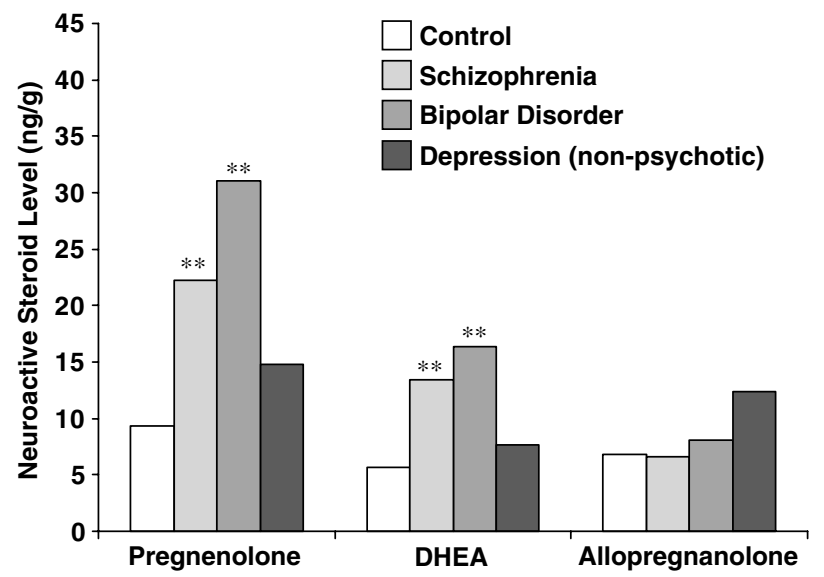

Figure 2 Median neuroactive steroid levels in posterior cingulate in control subjects without a psychiatric diagnosis and in patients with schizophrenia, bipolar disorder, and depression (nonpsychotic). Pregnenolone levels (log transformed) are significantly higher in posterior cingulate tissue from subjects with schizophrenia and bipolar disorder compared to control subjects (ANOVA $p=0.0017$; df 3,55; $F=5.73$; post hoc Dunnett ** $p<0.0$ I for both schizophrenia and bipolar disorder groups, $n=15$ per group). DHEA levels (log transformed) are significantly higher in posterior cingulate tissue from subjects with schizophrenia and bipolar disorder compared to control subjects (ANOVA $p=0.0015$; df 3,55; F = 5.84; post hoc Dunnett $* * * 0.0$ I for both schizophrenia and bipolar disorder groups, $n=15$ per group).

schizophrenia group, Figure 3. Allopregnanolone levels (log transformed) tended to be lower in parietal cortex tissue from subjects with schizophrenia compared to control subjects, Figure 3.

The neuroactive steroids pregnenolone and DHEA are therefore similarly altered in both brain regions tested
Table 2 Neuroactive Steroid Levels (ng/g) in Parietal Cortex

\begin{tabular}{|c|c|c|c|c|c|c|}
\hline & $\mathbf{N}$ & Min & QI & Med & Q3 & Max \\
\hline \multicolumn{7}{|l|}{ Pregnenolone } \\
\hline Control & 15 & 4.70 & 10.94 & 14.96 & 25.69 & 101.49 \\
\hline Schizophrenia & 15 & 5.87 & 21.70 & 40.42 & 52.94 & | 70.21 \\
\hline Bipolar & 15 & 9.29 & 17.76 & 41.14 & 139.84 & 331.86 \\
\hline Depression & 15 & 3.70 & 8.23 & 14.12 & 34.04 & 138.33 \\
\hline \multicolumn{7}{|l|}{ DHEA } \\
\hline Control & 15 & 0.82 & 3.67 & 6.04 & 10.59 & 33.21 \\
\hline Schizophrenia & 15 & 3.39 & 7.22 & 9.31 & 24.88 & 42.26 \\
\hline Bipolar & 15 & 4.63 & 6.38 & 18.33 & 30.80 & 41.92 \\
\hline Depression & 15 & 2.39 & 2.83 & 8.93 & 11.53 & 34.17 \\
\hline \multicolumn{7}{|l|}{ Allopregnanolone } \\
\hline Control & 15 & 5.20 & 7.44 & 11.42 & | 4.22 & 42.92 \\
\hline Schizophrenia & 15 & 4.13 & 5.40 & 7.16 & 10.09 & | I. 44 \\
\hline Bipolar & 15 & 3.01 & 6.37 & 7.42 & $12.9 \mid$ & 17.87 \\
\hline Depression & 15 & 3.89 & 4.86 & 9.02 & 10.68 & 16.82 \\
\hline
\end{tabular}

$N=$ number of subjects; $M$ in = minimum value in group; $\mathrm{Q} I=$ lower quartile; Med = median; $\mathrm{Q} 3=$ upper quartile; Max= maximum value in group.

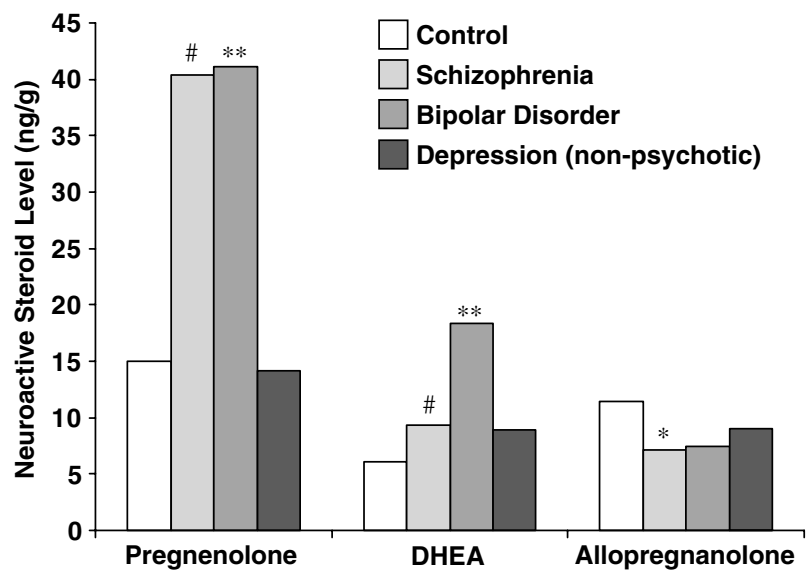

Figure 3 Median neuroactive steroid levels in parietal cortex in control subjects without a psychiatric diagnosis and in patients with schizophrenia, bipolar disorder, and depression (nonpsychotic). Pregnenolone levels (log transformed) were significantly higher in parietal cortex tissue from subjects with bipolar disorder compared to control subjects (ANOVA $p=0.0046$; df 3,56; $F=4.844$; post-hoc Dunnett $* * *<0.0$ I for the bipolar disorder group, $n=15$ ). Pregnenolone levels also tended to be higher in the schizophrenia group, but this finding was reduced to a trend in this brain region (post hoc Dunnett ${ }_{p} p=0.06, n=15$ ). DHEA levels (log transformed) were significantly higher in parietal cortex tissue in subjects with bipolar disorder compared to control subjects (ANOVA $p=0.0087$; df 3,56; $F=4.272$; post hoc Dunnett $* * * 0.0$ I for the bipolar disorder group, $n=15$ ). DHEA levels also tended to be higher in the schizophrenia group, but this finding was reduced to a trend in this brain region (post hoc Dunnett $\left.{ }^{\#} p=0.06, n=15\right)$. Allopregnanolone levels (log transformed) tended to be lower in parietal cortex tissue from subjects with schizophrenia compared to control subjects (ANOVA $p=0.09$ I I; df 3,$56 ; F=2.263$; post hoc Dunnett $* p=0.04$ for the schizophrenia group, $n=15)$.

(posterior cingulate and parietal cortex) in patients with schizophrenia and bipolar disorder. It is thus possible that pregnenolone may be preferentially metabolized to DHEA 
rather than allopregnanolone in these subjects, potentially leading to a shift toward DHEA formation and away from allopregnanolone synthesis (Figure 1). A preferential shift toward DHEA formation could potentially result in a net increase in neuronal excitation, since DHEA (which is increased in patients with schizophrenia and bipolar disorder) is a positive modulator of excitatory NMDA receptors and allopregnanolone (which tends to be decreased in patients with schizophrenia in parietal cortex) potentiates inhibitory $\mathrm{GABA}_{\mathrm{A}}$ receptor response.

\section{Secondary Analyses}

Preliminary findings in posterior cingulate and parietal cortex: neuroactive steroids analyzed separately by sex. Since a number of neuroactive steroids appear to be regulated differently in males and females, separate statistical analyses were conducted for posterior cingulate and parietal cortex neuroactive steroid levels in male and female subjects. These analyses should be viewed as preliminary and exploratory, given small sample sizes for male subjects $(n=8-9)$ and female subjects $(n=6)$ in each group. Briefly, significant findings persist in male subjects with schizophrenia and bipolar disorder (and may even be strengthened), but do not appear to persist in female subjects with these disorders in either posterior cingulate or parietal cortex, Table 3 . These findings may simply reflect decreased power in the analyses of the female subjects,

Table 3 Median Neuroactive Steroid Levels (ng/g) in Posterior Cingulate and Parietal Cortex in Males and Females

\begin{tabular}{|c|c|c|c|c|}
\hline & \multicolumn{2}{|c|}{ Posterior cingulate } & \multicolumn{2}{|c|}{ Parietal cortex } \\
\hline & Male & Female & Male & Female \\
\hline \multicolumn{5}{|l|}{ Pregnenolone } \\
\hline ANOVA $P$-value & 0.0014 & 0.128 & 0.0019 & 0.190 \\
\hline Control & 7.49 & 12.60 & 14.44 & 26.44 \\
\hline Schizophrenia & $31.45^{* * *}$ & 13.55 & $44.87 * *$ & 27.66 \\
\hline Bipolar & $21.45^{* * *}$ & 37.63 & $35.30 *$ & 63.41 \\
\hline Depression & 11.44 & 18.62 & 12.50 & 33.85 \\
\hline
\end{tabular}

DHEA

$\begin{array}{lcccc}\text { ANOVA P-value } & <0.0001 & 0.542 & 0.0004 & 0.652 \\ \text { Control } & 5.17 & 6.51 & 4.87 & 6.49 \\ \text { Schizophrenia } & 17.39 * * * & 8.00 & 16.15 * & 6.86 \\ \text { Bipolar } & 19.81 * * * & 11.68 & 29.55 * * & 12.17 \\ \text { Depression } & 4.87 & 11.08 & 4.14 & 9.12\end{array}$

\begin{tabular}{llllc} 
Allopregnanolone & & & & \\
ANOVA P-value & 0.164 & 0.810 & 0.478 & 0.283 \\
Control & 6.42 & 8.53 & 8.80 & 12.40 \\
Schizophrenia & 6.55 & 7.51 & 7.16 & 7.38 \\
Bipolar & 8.12 & 7.98 & 7.00 & 10.43 \\
Depression & 13.75 & 3.03 & 8.63 & 9.84 \\
\hline
\end{tabular}

ANOVAs performed on log-transformed neuroactive steroid levels.

Post hoc Dunnett's test $* p<0.05, * *{ }^{*} p<0.0$ I, ***** $p<0.00$ I however, since there are 50\% fewer subjects in this group compared to male subjects (hence introducing the possibility of Type II error). Findings will clearly require replication in a larger cohort.

Neuroactive steroids and clozapine. Median levels of the neuroactive steroid allopregnanolone were higher in posterior cingulate (but not parietal cortex) in patients with schizophrenia or bipolar disorder who were receiving clozapine at the time of death $(12.45 \mathrm{ng} / \mathrm{g}, n=7)$ compared to those who were not receiving clozapine at this time point $(7.44 \mathrm{ng} / \mathrm{g}, n=23)$; however, these differences did not achieve statistical significance (Mann-Whitney $U$-test statistic $p>0.05)$. Median DHEA levels were lower in patients receiving clozapine $(7.70 \mathrm{ng} / \mathrm{g}, n=7)$ compared to subjects who were not receiving clozapine $(18.33 \mathrm{ng} / \mathrm{g}$, $n=23$ ), but these differences were also not statistically significant (Mann-Whitney $U$-test statistic $p>0.05$ ). Similarly, analyses within the schizophrenia and bipolar groups comparing subjects receiving clozapine to those who were not receiving clozapine at the time of death were not statistically significant. It is possible, however, that the small number of subjects in the clozapine-treated group(s) resulted in reduced statistical power and the introduction of Type II error in this cohort.

Neuroactive steroids and lifetime antipsychotic exposure. In posterior cingulate (but not parietal cortex), allopregnanolone levels tended to be positively correlated with lifetime antipsychotic exposure (in fluphenazine equivalents) in schizophrenia subjects (Pearson's $r=0.45, p=0.094$, $n=15$ ) and bipolar disorder subjects (Pearson's $r=0.47$, $p=0.077, n=15$ ). The absence of significant correlations may not be entirely unexpected, since only $\sim 33 \%$ of patients with schizophrenia $(n=5)$ and $\sim 13 \%$ of patients with bipolar disorder $(n=2)$ in this study were receiving clozapine at the time of death (none were receiving olanzapine), and the conventional antipsychotic haloperidol and the second generation antipsychotic risperidone do not appear to alter neuroactive steroids in rodent models (Marx et al, 2003; Barbaccia et al, 2001; Trost et al, 2005).

\section{DISCUSSION}

A primary finding in this investigation is that a number of neuroactive steroids (pregnenolone, DHEA, allopregnanolone) are present in human post-mortem brain tissue at physiologically relevant concentrations in the nanomolar range. For example, pregnenolone and DHEA (Flood et al, 1992) and pregnenolone sulfate (Flood et al, 1992, 1995; Akwa et al, 2001) enhance learning and memory in rodents at low nanomolar concentrations. These DHEA, pregnenolone, and pregnenolone sulfate actions may therefore be particularly relevant to cognitive deficits observed in subjects with schizophrenia. DHEA and DHEAS also have trophic effects on axonal and dendritic outgrowth, respectively, at similar concentrations (Compagnone and Mellon, 1998), and allopregnanolone positively modulates $\mathrm{GABA}_{\mathrm{A}}$ receptors at low nanomolar concentrations (Morrow et al, 1987, 1990). Since decreased neuropil (Glantz and Lewis, 2000; Harrison and Weinberger, 2005, review) and changes 
in the GABA neurotransmitter system (Benes and Berretta, 2001; Wassef et al, 2003; Costa et al, 2004; Lewis et al, 2004; Coyle, 2004) are consistent findings in the schizophrenia literature, neuroactive steroids may be candidate modulators of these alterations and merit investigation. In addition, evidence suggests that patients with bipolar disorder may also demonstrate neuropil reductions (Gray et al, 2003, review). Pregnenolone, DHEA, and allopregnanolone may therefore have a functional impact on a number of different neurophysiological processes that are relevant to schizophrenia and bipolar disorder. To our knowledge, this is the first investigation to report neuroactive steroid levels in postmortem brain tissue from subjects with these disorders.

Our primary analyses determined that pregnenolone and DHEA levels were higher in subjects with schizophrenia and bipolar disorder compared to control subjects in both posterior cingulate and parietal cortex. The precise significance of these neuroactive steroid elevations in two brain regions in patients with schizophrenia and bipolar disorder is currently unclear, and a number of questions remain. For example, could higher levels be the result of enhanced biosynthesis and/or decreased metabolism to downstream neuroactive steroids, reflecting changes in the regulation of biosynthetic pathways? Could these changes potentially alter the regulation of excitatory and/or inhibitory neurotransmission? Do these increases reflect compensatory upregulation, pathologic dysregulation, or epiphenomena? We provide a brief framework for these and other inquiries below.

In our secondary analyses, neuroactive steroid findings appear to persist in male subjects with schizophrenia and bipolar disorder when neuroactive steroid levels are analyzed separately by sex, but this may not be the case for female subjects with these disorders (although the possibility of Type II error cannot be excluded, given smaller sample sizes in the female groups). Our secondary analyses addressing antipsychotic exposure did not result in significant findings, but possible trends emerged and are discussed below.

\section{Potential Changes in the Regulation of Neuroactive Steroid Biosynthetic Pathways in Schizophrenia and Bipolar Disorder}

The regulation of neuroactive steroids in the brain is likely exceedingly complex, as these molecules are components of dynamic biosynthetic pathways that include both reversible and irreversible reactions and encompass a hundred or more steroids. In the current investigation, pregnenolone and DHEA are elevated in subjects with schizophrenia and bipolar disorder in both posterior cingulate and parietal cortex. Since pregnenolone is a potential precursor for many steroids, it is important to consider downstream pregnenolone metabolite effects that include a large number of possibilities and a myriad of combinations. For example, pregnenolone can be metabolized to neuroactive steroids that have opposite effects on $\mathrm{GABA}_{\mathrm{A}}, \mathrm{NMDA}$, and other membrane-bound ligand-gated ion channel receptors, potentially resulting in a highly versatile mechanism impacting the regulation of net inhibitory or excitatory neurotransmission. This investigation suggests that pregnenolone may be preferentially metabolized to DHEA rather than allopregnanolone in subjects with schizophrenia and bipolar disorder. Since both pregnenolone sulfate and DHEA are positive modulators of excitatory NMDA receptors and allopregnanolone is a potent positive modulator of inhibitory $\mathrm{GABA}_{\mathrm{A}}$ receptors, the neuroactive steroid milieu in subjects with schizophrenia and bipolar disorder may be one of a net increase in neuronal excitation. Neuroactive steroid alterations may therefore represent a possible mechanism for the complex orchestration of major brain neurotransmitter systems in patients with schizophrenia and bipolar disorder.

Also potentially relevant to the regulation of neuroactive steroid biosynthetic pathways, genes involved in cholesterol biosynthesis appear to be downregulated in subjects with schizophrenia (Prabakaran et al, 2004). Since cholesterol is a precursor for all steroids, alterations in cholesterol synthesis may also impact downstream neuroactive steroid metabolites. Conversely, upregulated pathways in patients with schizophrenia appear to include a metabolism pathway encompassing transcripts of the P450scc (CYP11A1) gene encoding the enzyme catalyzing the conversion of cholesterol to pregnenolone, and the START domain in the outer mitochondrial membrane, among others (Prabakaran et al, 2004). Although no significant changes were observed in transcripts for these individual genes utilizing stringent criteria addressing multiple comparisons, significant upregulation in the overall hormone metabolism pathway that was targeted suggests that neuroactive steroid regulation may be altered in schizophrenia (Prabakaran et al, 2004). These steroid metabolism pathway changes may therefore represent a potential mechanism for higher levels of pregnenolone and DHEA (a pregnenolone metabolite) in subjects with schizophrenia.

\section{Neuroactive Steroid Alterations and Possible Ramifications for Glutamatergic and GABAergic Neurotransmission}

Pregnenolone and DHEA are elevated in two brain regions in subjects with schizophrenia and bipolar disorder in these investigations. Since both pregnenolone sulfate and DHEA demonstrate positive modulatory actions at NMDA receptors, the glutamatergic neurotransmitter system may be impacted by these alterations in posterior cingulate and parietal cortex. Relevant to this possibility, the glutamatergic neurotransmitter system may be altered in subjects with schizophrenia and is theorized to be a logical target for the development of new therapeutic strategies (Javitt, 2004, review). It has been demonstrated that NMDA antagonists such as ketamine are psychotomimetic, exacerbating psychotic symptoms in subjects with schizophrenia and inducing psychotic symptoms in healthy control subjects (Krystal et al, 1994; Malhotra et al, 1997; Lahti et al, 1995, 2001). These findings have informed the hypothesis that NMDA receptor hypofunction represents a key component of schizophrenia pathophysiology. Since pregnenolone sulfate and DHEA have positive modulatory actions at NMDA receptors (Irwin et al, 1994; Wu et al, 1991; Compagnone and Mellon, 1998; Debonnel et al, 1996; Bergeron et al, 1996; Sliwinski et al, 2004) and increase learning and memory in rodent models (Flood et al, 1992, 1995; Akwa et al, 2001; Vallee et al, 1997, 2003), elevated 
levels of these compounds could have therapeutic value. The NMDA receptor antagonist D-2-amino-5-phosphonovalerate (D-AP5) prevents the memory-enhancing effect of pregnenolone sulfate, suggesting this action may involve NMDA receptors (Akwa et al, 2001). Pregnenolone sulfate administration also prevents cognitive deficits following the NMDA receptor antagonists dizoclipine maleate (MK-801) and D-AP5 (Romeo et al, 1994; Mathis et al, 1996), supporting the possibility that NMDA receptor modulation contributes to the positive actions of this neuroactive steroid on learning and memory. Furthermore, pregnenolone sulfate appears to increase long-term potentiation in rat hippocampus by an NMDA receptor-mediated mechanism (Sliwinski et al, 2004). Elevations in pregnenolone and DHEA in posterior cingulate and parietal cortex may thus be relevant to hypothesized NMDA receptor hypofunction and cognitive symptoms in patients with schizophrenia.

\section{Neuroactive Steroid Alterations in Schizophrenia and Bipolar Disorder: Compensatory Upregulation vs Pathological Dysregulation, and Potential Impact on Brain Function}

Neuroactive steroids and neuroprotection. DHEA levels are elevated in subjects with schizophrenia and bipolar disorder in posterior cingulate and parietal cortex, and these changes may impact brain function. For example, DHEA is neuroprotective against a number of insults resulting in oxidative stress, and these protective actions may be relevant to schizophrenia pathophysiology. DHEA and its sulfated derivative DHEAS protect neurons against NMDA-induced excitotoxicity (Kimonides et al, 1998; Kurata et al, 2004) and anoxia (Marx et al, 2000b) in rodent models. DHEA also protects neurons against glutamate and amyloid $\beta$-protein toxicity (Cardounel et al, 1999), $\mathrm{CuSO}_{4}$-induced oxidative damage (Boccuzzi et al, 1997), $\mathrm{H}_{2} \mathrm{O}_{2} / \mathrm{FeSO}_{4}$-stimulated lipid oxidation (Bastianetto et al, 1999), and hyperglycemia-induced toxicity (Aragno et al, 1997). In addition, DHEA appears to have direct actions on mitochondrial function, dose dependently protecting mitochondrial membranes from anoxia-reoxygenation oxidative stress (Morin et al, 2002). Since DHEA levels are elevated in two brain regions in subjects with schizophrenia and bipolar disorder in the current investigation, it is possible these alterations may result in neuroprotection against oxidative stressors and represent an adaptive change. Initial evidence suggests that administering agents known to induce oxidative stress, such as ferrous sulfate and $\beta$-amyloid peptide, result in increased DHEA formation (Brown et al, 2003). Oxidative stressors my therefore precede and possibly precipitate elevated DHEA levels observed in these investigations.

Neuroactive steroids and myelination. Pregnenolone and DHEA elevations in subjects with schizophrenia and bipolar disorder may be relevant to the regulation of myelination in these disorders. Changes in cholesterol biosynthetic pathways in patients with schizophrenia (Prabakaran et al, 2004) likely also impact myelination processes, since cholesterol is a critical myelin component and genes involved in cholesterol synthesis and myelin formation are coregulated (Nagarajan et al, 2002). Converging evidence from micro- array (Hakak et al, 2001; Tkachev et al, 2003) and neuroimaging (Szeszko et al, 2005) investigations suggest a dysregulation in myelination in schizophrenia. Efforts demonstrating alterations in myelin-producing oligodendrocytes in patients with schizophrenia also support this possibility (Uranova et al, 2001; Hof et al, 2003). Since an expanding literature suggests a role for neuroactive steroids in the regulation of myelination, it is possible that neuroactive steroid alterations observed in this investigation may impact this component of schizophrenia pathophysiology. For example, pregnenolone increases myelin sheath thickness following sciatic nerve cryolesion (Koenig et al, 1995). Also implicating a modulatory role for neuroactive steroids in myelination, chronic pregnenolone treatment improved locomotor behavior in myelin mutant mice (Bloom et al, 2002). DHEA treatment increases the number of myelinated fibers in rat sciatic nerve and enhances functional recovery following crush injury $(\mathrm{Gu}-$ demez et al, 2002), and increases axonal outgrowth in vitro (Compagnone and Mellon, 1998). Allopregnanolone increases myelin basic protein expression in vitro (Ghoumari et al, 2003), and deficits in this neuroactive steroid have been linked to neurodegenerative disorders in which myelination is dysregulated, including Neimann-Pick type C disease (Mellon et al, 2004) and Alzheimer's disease (Trost et al, 2004). Together these investigations suggest a positive modulatory role for neuroactive steroids in myelination, and it is therefore possible that pregnenolone and DHEA elevations in subjects with schizophrenia represent a compensatory upregulation of these neuroactive steroids.

Neuroactive steroids as candidate modulators of stress regulation. DHEA levels were higher in both posterior cingulate and parietal cortex in subjects with schizophrenia and bipolar disorder compared to control subjects, yet the administration of exogenous DHEA as an augmentation strategy appears to have therapeutic effects on negative, depressive, and anxiety symptoms in patients with schizophrenia (Strous et al, 2003). Since DHEA has positive modulatory actions on NMDA receptors (Debonnel et al, 1996; Bergeron et al, 1996) and also enhances learning and memory in rodent models (Flood et al, 1992; Vallee et al, 2001), it is tempting to speculate that DHEA elevations in brain may reflect a compensatory process. It is also possible that subjects with schizophrenia and bipolar disorder may be physiologically resistant to DHEA actions in some manner (potentially resulting in the increased formation of this neuroactive steroid), or that there is dysregulation in a feedback system involving the hypothalamic-pituitaryadrenal (HPA) axis. Specifically, DHEA increases following corticotrophin-releasing hormone (CRH) (Genazzani et al, 1998; Bernardi et al, 2000) and ACTH administration (Rasmusson et al, 2004) in humans, and therefore persistent DHEA elevations may reflect a prolonged upregulation of the HPA axis. DHEA also demonstrates antiglucocorticoid actions (Kimonides et al, 1999; Karishma and Herbert, 2002; $\mathrm{Hu}$ et al, 2000; Kalimi et al, 1994), supporting a role for DHEA in HPA axis regulation. DHEA administration to human subjects appears to result in significantly higher serum allopregnanolone and lower cortisol levels (Genazzani et al, 2003), and these findings may be consistent with allopregnanolone-induced decreases in $\mathrm{CRH}, \mathrm{ACTH}$, and 
corticosterone release observed in rodents (Patchev et al, 1994, 1996; Guo et al, 1995) and DHEA antiglucocorticoid effects. Increased DHEA levels in subjects with schizophrenia and bipolar disorder and a trend for decreased allopregnanolone levels in parietal cortex in subjects with schizophrenia may therefore be relevant to HPA axis regulation and stress modulation.

\section{Neuroactive Steroids and Potential Implications for Sex Differences in Schizophrenia and Bipolar Disorder}

An extensive literature documents sex differences in the epidemiology and course of patients with schizophrenia. Female patients with schizophrenia demonstrate a later age of onset, better premorbid functioning, and fewer negative symptoms than male subjects with the disorder (reviews Seeman, 2004; Tamminga, 1997; Hafner, 2003; Aleman et al, 2003). Imaging investigations suggest that female patients with schizophrenia may demonstrate fewer structural brain alterations compared to male subjects with the disorder (Andreasen et al, 1990; Nopoulos et al, 1997; Gur et al, 2000; Goldstein et al, 2002). In addition, there appear to be sex differences in functional connectivity (Slewa-Younan et al, 2004) and neuropsychological correlates to hippocampal volumes (Szeszko et al, 2002) in patients with schizophrenia. It has been hypothesized that the hormonal environment is neuroprotective in some manner in female patients with schizophrenia (Halbreich and Kahn, 2003; Hafner, 2003; Seeman, 2004), but the precise neurobiology of these sex differences has remained elusive. Similarly to schizophrenia, there also appear to be sex differences in the age of onset of mania and bipolar disorder, with males demonstrating earlier onset after controlling for premorbid factors (Kennedy et al, 2005). Female subjects with bipolar disorder may be more likely to demonstrate depressive episodes and rapid-cycling (Arnold, 2003, review), and there appear to be sex differences in vesicular monoamine transporter binding in bipolar patients (Zubieta et al, 2000). Sex differences therefore appear relevant to the pathophysiologies of both schizophrenia and bipolar disorder.

Our analyses demonstrate that significant pregnenolone and DHEA elevations persist (and may possibly be strengthened) in male patients with schizophrenia and bipolar disorder in both posterior cingulate and parietal cortex when data are analyzed separately by sex. When female subjects are analyzed separately, however, these pregnenolone and DHEA findings do not appear to persist in either brain region. It is therefore possible that pregnenolone and DHEA elevations in patients with schizophrenia and bipolar disorder may be specific to males, potentially yielding clues to the neurobiology of sex differences in these disorders. These secondary analyses are exploratory, however, and the possibility of sex differences in brain neuroactive steroid levels must be tempered with acknowledgement that sample sizes in female subjects are very limited ( $n=6$ per group), and that these female groups may thus be too small to detect differences. Nonetheless, separate analyses by sex were very similar in both posterior cingulate and parietal cortex, potentially providing initial evidence that neuroactive steroids may represent candidate modulators of sex differences in these disorders. Replication of these findings in a larger cohort of subjects will be required to test this possibility, and to inform future hypotheses regarding the relevance of neuroactive steroids to the clinical manifestations of sex differences in schizophrenia and bipolar disorder.

\section{Antipsychotic Drug Exposure and Neuroactive Steroids}

Based on prior rodent findings (Marx et al, 2000a, 2003; Barbaccia et al, 2001; Trost et al, 2005), we hypothesized that patients with schizophrenia or bipolar disorder receiving clozapine at the time of death would demonstrate elevated allopregnanolone levels compared to subjects with these disorders receiving conventional antipsychotics, no antipsychotic, or risperidone at this time point. Although median allopregnanolone levels were $67 \%$ higher in patients receiving clozapine compared to those who were not receiving clozapine, this difference did not achieve statistical significance. The analysis was limited by small sample size, however, since only seven patients were receiving clozapine at the time of death. The concurrent use of other psychiatric medications is also potentially confounding. For example, the selective serotonin reuptake inhibitor (SSRI) fluoxetine increases brain allopregnanolone levels in rodent models (Uzunov et al, 1996) and appears to increase cerebrospinal fluid allopregnanolone levels in patients with depression (Uzunova et al, 1998). Carbamazepine also appears to increase allopregnanolone levels in rodents (Serra et al, 2000). A total of four subjects with schizophrenia or bipolar disorder were receiving SSRIs at the time of death (two in each group) and three subjects were receiving carbamazepine (one and two in each group, respectively), but neither SSRI nor carbamazepine status appeared related to neuroactive steroid levels in patients with these disorders (data not shown). Analyses addressing medication status at the time of death with regard to agents hypothesized to alter neuroactive steroid levels are clearly challenging. Limitations include small sample sizes, substantial numbers of patients receiving more than one psychiatric medication at the time of death (10/15 and 12/ 15 patients with schizophrenia and bipolar disorder, respectively), and the presence of a number of agents known to alter neuroactive steroid levels in rodents.

Allopregnanolone levels tended to be positively correlated with lifetime antipsychotic exposure in both schizophrenia and bipolar disorder in posterior cingulate, but these results did not achieve statistical significance and trends were observed in only one brain region. Lifetime antipsychotic exposure is very difficult to assess, however, and it is possible that these estimates add variability to the sample. Although clozapine and olanzapine dose dependently increase allopregnanolone in rodents, antipsychotic-induced neuroactive steroid changes following haloperidol or risperidone were not detected in animal models (Marx et al, 2003; Barbaccia et al, 2001; Trost et al, 2005). Since neuroactive steroid changes appear specific to the administration of certain second generation antipsychotics in rodents, it might be expected that correlations would be less strong in a mixed cohort of subjects exposed to both conventional and second generation agents. Analyzing a variable that converts two classes of antipsychotics to a single common denominator (ie fluphenazaine equivalents) may thus be somewhat limited. 


\section{Study Limitations and Potential Confounding Factors}

A major study limitation is small sample size $(n=15$ in each group), a challenge confronting many human post-mortem tissue investigations. Given the scarcity of well-characterized samples from patients with psychiatric disorders, however, this limitation is not unexpected. Data regarding neuroactive steroid levels in human brain tissue are extremely limited, as previously discussed. To address potential confounding elements, we must therefore extrapolate from rodent investigations and human studies in the periphery. Possible confounders in this investigation include uncontrolled medication status at the time of death, as discussed above. In addition, both acute (Morrow et al, 1995; Girdler et al, 2001; Purdy et al, 1991; Barbaccia et al, 1998; Vallee et al, 2000) and chronic (Dong et al, 2001; Pinna et al, 2003; Wolkowitz et al, 2001) stressors impact neuroactive steroid levels in rodent brain and human plasma, and it is possible that a number of stressors may also alter neuroactive steroid levels in human brain. Smoking also increases DHEA levels (Field et al, 1994; Feldman et al, 1998; Mendelson et al, 2005), and we have recently determined that serum levels of allopregnanolone are correlated with salivary levels of cotinine (a nicotine metabolite) in subjects with nicotine dependence (Marx et al, in press). Nicotine also elevates neuroactive steroid levels in rodent models (Porcu et al, 2003). Smoking status at the time of death is hence an important potential confounder, given high rates of nicotine dependence in patients with schizophrenia and bipolar disorder. Unfortunately, tobacco history is not currently available for this cohort of subjects. Alcohol use may also alter neuroactive steroid levels (VanDoren et al, 2000; Pierucci-Lagha et al, in press). In addition, it is possible that menstrual cycle phase in female premenopausal subjects (and hormone replacement status in postmenopausal subjects) may affect neuroactive steroid levels in human brain, since rodent evidence suggests that central allopregnanolone levels fluctuate across the estrous cycle (Purdy et al, 1990; Corpechot et al, 1997; Frye and Bayon, 1998). Peripheral plasma allopregnanolone levels also demonstrate variability across the menstrual cycle in humans (Genazzani et al, 1998, 2002; Paul and Purdy, 1992; Pearson Murphy and Allison, 2000). Menstrual cycle phase data and hormone replacement status are unfortunately not available for this tissue collection. Since it was not feasible to control for these variables in female subjects, it is quite possible that they may represent additional confounding elements in our analyses of female patients, potentially contributing to the loss of a statistically significant signal. Finally, it is unknown if any patients were receiving cholesterol-lowering medications at the time of death. Since it is theoretically possible that decreasing cholesterol precursor could influence downstream steroid formation, this could also constitute a potential confounder.

\section{Conclusions}

Neuroactive steroids represent candidate modulators of schizophrenia and bipolar disorder pathophysiology and therapeutics. The neuroactive steroids pregnenolone and DHEA are elevated in subjects with schizophrenia and bipolar disorder in both posterior cingulate and parietal cortex. Since the number of subjects in this investigation is small, results will require replication in a larger cohort. Nonetheless, very similar neuroactive steroid profiles were observed in two brain regions utilizing a highly sensitive and specific mass spectrometry-based method. Furthermore, pregnenolone, DHEA, and allopregnanolone levels determined in human post-mortem brain in these investigations are known to be physiologically relevant, suggesting that neuroactive steroid alterations in schizophrenia and bipolar disorder may have a functional impact on the pathophysiology of these disorders and do not merely represent epiphenomena. In addition, neuroactive steroid induction represents a potential mechanism contributing to the efficacy of several antipsychotic agents, and therefore these molecules merit further investigation as targets for pharmacological intervention. Future efforts will be required to characterize the precise regulation of neuroactive steroids in human brain, but initial findings that these molecules are significantly altered in postmortem brain tissue from subjects with schizophrenia and bipolar disorder suggest a role for neuroactive steroids in these disorders.

\section{ACKNOWLEDGEMENTS}

NIH K23 MH65080 (CEM), NARSAD (CEM), VISN 6 MIRECC (PI Gregory McCarthy, PhD), VA REAP (PI Roger D Madison, PhD), T32 MH70448 (PI Dan G Blazer, MD PhD), and The Stanley Foundation Neuropathology Consortium for generously providing brain tissue. We thank Gillian Parke for her excellent assistance in the preparation of this manuscript.

\section{REFERENCES}

Akwa Y, Ladurelle N, Covey DF, Baulieu EE (2001). The synthetic enantiomer of pregnenolone sulfate is very active on memory in rats and mice, even more so than its physiological neurosteroid counterpart: distinct mechanisms? Proc Natl Acad Sci USA 98: 14033-14037.

Aleman A, Kahn RS, Selten JP (2003). Sex differences in the risk of schizophrenia: evidence from meta-analysis. Arch Gen Psychiatr 60: $565-571$.

Andreasen NC, Ehrhardt JC, Swayze II VW, Alliger RJ, Yuh WT, Cohen $\mathrm{G}$ et al (1990). Magnetic resonance imaging of the brain in schizophrenia. The pathophysiologic significance of structural abnormalities. Arch Gen Psychiatr 47: 35-44.

Aragno M, Brignardello E, Tamagno E, Gatto V, Danni O, Boccuzzi G (1997). Dehydroepiandrosterone administration prevents the oxidative damage induced by acute hyperglycemia in rats. J Endocrinol 155: 233-240.

Arnold LM (2003). Gender differences in bipolar disorder. Psychiatr Clin North Am 26: 595-620.

Barbaccia ML, Affricano D, Purdy RH, Maciocco E, Spiga F, Biggio G (2001). Clozapine, but not haloperidol, increases brain concentrations of neuroactive steroids in the rat. Neuropsychopharmacology 25: 489-497.

Barbaccia ML, Concas A, Serra M, Biggio G (1998). Stress and neurosteroids in adult and aged rats. Exp Gerontol 33: 697-712.

Bastianetto S, Ramassamy C, Poirier J, Quirion R (1999). Dehydroepiandrosterone (DHEA) protects hippocampal cells from oxidative stress-induced damage. Brain Res Mol Brain Res 66: $35-41$. 
Baulieu EE, Robel P, Schumacher M (2001). Neurosteroids: beginning of the story. Int Rev Neurobiol 46: 1-32.

Belelli D, Bolger MB, Gee KW (1989). Anticonvulsant profile of the progesterone metabolite 5 alpha-pregnan-3 alpha-ol-20-one. Eur J Pharmacol 166: 325-329.

Benes FM, Berretta S (2001). GABAergic interneurons: implications for understanding schizophrenia and bipolar disorder. Neuropsychopharmacology 25: 1-27.

Bergeron R, de Montigny C, Debonnel G (1996). Potentiation of neuronal NMDA response induced by dehydroepiandrosterone and its suppression by progesterone: effects mediated via sigma receptors. J Neurosci 16: 1193-1202.

Bernardi F, Lanzone A, Cento RM, Spada RS, Pezzani I, Genazzani $\mathrm{AD}$ et al (2000). Allopregnanolone and dehydroepiandrosterone response to corticotropin-releasing factor in patients suffering from Alzheimer's disease and vascular dementia. Eur $J$ Endocrinol 142: 466-471.

Bixo M, Andersson A, Winblad B, Purdy RH, Backstrom T (1997). Progesterone, 5alpha-pregnane-3,20-dione and 3alpha-hydroxy-5alpha-pregnane-20-one in specific regions of the human female brain in different endocrine states. Brain Res 764: 173-178.

Bjornerem A, Straume B, Midtby M, Fonnebo V, Sundsfjord J, Svartberg J et al (2004). Endogenous sex hormones in relation to age, sex, lifestyle factors, and chronic diseases in a general population: the Tromso Study. J Clin Endocrinol Metab 89: 6039-6047.

Bloom CM, Anch AM, Dyche JS (2002). Behavioral effects of chronic melatonin and pregnenolone injections in a myelin mutant rat (taiep). J Gen Psychol 129: 226-237.

Boccuzzi G, Aragno M, Seccia M, Brignardello E, Tamagno E, Albano E et al (1997). Protective effect of dehydroepiandrosterone against copper-induced lipid peroxidation in the rat. Free Radic Biol Med 22: 1289-1294.

Bowlby MR (1993). Pregnenolone sulfate potentiation of $N$-methylD-aspartate receptor channels in hippocampal neurons. Mol Pharmacol 43: 813-819.

Brown RC, Han Z, Cascio C, Papadopoulos V (2003). Oxidative stress-mediated DHEA formation in Alzheimer's disease pathology. Neurobiol Aging 24: 57-65.

Cannon TD, Rosso IM, Bearden CE, Sanchez LE, Hadley T (1999). A prospective cohort study of neurodevelopmental processes in the genesis and epigenesis of schizophrenia. Dev Psychopathol 11: 467-485.

Cannon TD, Rosso IM, Hollister JM, Bearden CE, Sanchez LE, Hadley T (2000). A prospective cohort study of genetic and perinatal influences in the etiology of schizophrenia. Schizophr Bull 26: 351-366.

Cardounel A, Regelson W, Kalimi M (1999). Dehydroepiandrosterone protects hippocampal neurons against neurotoxininduced cell death: mechanism of action. Proc Soc Exp Biol Med 222: 145-149.

Compagnone NA, Mellon SH (1998). Dehydroepiandrosterone: a potential signalling molecule for neocortical organization during development. Proc Natl Acad Sci USA 95: 4678-4683.

Corpechot C, Collins BE, Carey MP, Tsouros A, Robel P, Fry JP (1997). Brain neurosteroids during the mouse oestrous cycle. Brain Res 766: 276-280.

Costa E, Davis JM, Dong E, Grayson DR, Guidotti A, Tremolizzo L et al (2004). A GABAergic cortical deficit dominates schizophrenia pathophysiology. Crit Rev Neurobiol 16: 1-23.

Coyle JT (2004). The GABA-glutamate connection in schizophrenia: which is the proximate cause? Biochem Pharmacol 68: 1507-1514.

Dalman C, Thomas HV, David AS, Gentz J, Lewis G, Allebeck P (2001). Signs of asphyxia at birth and risk of schizophrenia. Population-based case-control study. $\mathrm{Br} J$ Psychiatr 179: 403-408.
Danckert J, Saoud M, Maruff P (2004). Attention, motor control and motor imagery in schizophrenia: implications for the role of the parietal cortex. Schizophr Res 70: 241-261.

Darnaudery M, Koehl M, Pallares M, Le Moal M, Mayo W (1998). The neurosteroid pregnenolone sulfate increases cortical acetylcholine release: a microdialysis study in freely moving rats. $J$ Neurochem 71: 2018-2022.

Darnaudery M, Pallares M, Piazza PV, Le Moal M, Mayo W (2002). The neurosteroid pregnenolone sulfate infused into the medial septum nucleus increases hippocampal acetylcholine and spatial memory in rats. Brain Res 951: 237-242.

Debonnel G, Bergeron R, de Montigny C (1996). Potentiation by dehydroepiandrosterone of the neuronal response to $\mathrm{N}$-methyl$\mathrm{D}$-aspartate in the CA3 region of the rat dorsal hippocampus: an effect mediated via sigma receptors. J Endocrinol 150(Suppl): S33-S42.

Devaud LL, Purdy RH, Morrow AL (1995). The neurosteroid, 3 alpha-hydroxy-5 alpha-pregnan-20-one, protects against bicuculline-induced seizures during ethanol withdrawal in rats. Alcohol Clin Exp Res 19: 350-355.

Dong E, Matsumoto K, Uzunova V, Sugaya I, Takahata H, Nomura $\mathrm{H}$ et al (2001). Brain 5alpha-dihydroprogesterone and allopregnanolone synthesis in a mouse model of protracted social isolation. Proc Natl Acad Sci USA 98: 2849-2854.

Feldman HA, Johannes CB, McKinlay JB, Longcope C (1998). Low dehydroepiandrosterone sulfate and heart disease in middleaged men: cross-sectional results from the Massachusetts Male Aging Study. Ann Epidemiol 8: 217-228.

Field AE, Colditz GA, Willett WC, Longcope C, McKinlay JB (1994). The relation of smoking, age, relative weight, and dietary intake to serum adrenal steroids, sex hormones, and sex hormone-binding globulin in middle-aged men. J Clin Endocrinol Metab 79: 1310-1316.

Flood JF, Morley JE, Roberts E (1992). Memory-enhancing effects in male mice of pregnenolone and steroids metabolically derived from it. Proc Natl Acad Sci USA 89: 1567-1571.

Flood JF, Morley JE, Roberts E (1995). Pregnenolone sulfate enhances post-training memory processes when injected in very low doses into limbic system structures: the amygdala is by far the most sensitive. Proc Natl Acad Sci USA 92: 10806-10810.

Frye CA, Bayon LE (1998). Seizure activity is increased in endocrine states characterized by decline in endogenous levels of the neurosteroid 3 alpha, 5 alpha-THP. Neuroendocrinology 68: $272-280$.

Geddes JR, Verdoux H, Takei N, Lawrie SM, Bovet P, Eagles JM et al (1999). Schizophrenia and complications of pregnancy and labor: an individual patient data meta-analysis. Schizophr Bull 25: 413-423.

Gee KW, Bolger MB, Brinton RE, Coirini H, McEwen BS (1988). Steroid modulation of the chloride ionophore in rat brain: structure-activity requirements, regional dependence and mechanism of action. J Pharmacol Exp Ther 246: 803-812.

Genazzani AD, Luisi M, Malavasi B, Strucchi C, Luisi S, Casarosa E et al (2002). Pulsatile secretory characteristics of allopregnanolone, a neuroactive steroid, during the menstrual cycle and in amenorrheic subjects. Eur J Endocrinol 146: 347-356.

Genazzani AD, Stomati M, Bernardi F, Pieri M, Rovati L, Genazzani AR (2003). Long-term low-dose dehydroepiandrosterone oral supplementation in early and late postmenopausal women modulates endocrine parameters and synthesis of neuroactive steroids. Fertil Steril 80: 1495-1501.

Genazzani AR, Petraglia F, Bernardi F, Casarosa E, Salvestroni C, Tonetti A et al (1998). Circulating levels of allopregnanolone in humans: gender, age, and endocrine influences. J Clin Endocrinol Metab 83: 2099-2103.

George M, Guidotti A, Rubinow D, Pan B, Mikalauskas K, Post R (1994). CSF neuroactive steroids in affective disorders: pregnenolone, progesterone, and DBI. Biol Psychiatr 35: 775-780. 
Ghoumari AM, Ibanez C, El-Etr M, Leclerc P, Eychenne B, O'Malley BW et al (2003). Progesterone and its metabolites increase myelin basic protein expression in organotypic slice cultures of rat cerebellum. J Neurochem 86: 848-859.

Girdler SS, Straneva PA, Light KC, Pedersen CA, Morrow AL (2001). Allopregnanolone levels and reactivity to mental stress in premenstrual dysphoric disorder. Biol Psychiatr 49: 788-797.

Glantz LA, Lewis DA (2000). Decreased dendritic spine density on prefrontal cortical pyramidal neurons in schizophrenia. Arch Gen Psychiatr 57: 65-73.

Goldstein JM, Seidman LJ, O’Brien LM, Horton NJ, Kennedy DN, Makris $\mathrm{N}$ et al (2002). Impact of normal sexual dimorphisms on sex differences in structural brain abnormalities in schizophrenia assessed by magnetic resonance imaging. Arch Gen Psychiatr 59: 154-164.

Gray NA, Zhou R, Du J, Moore GJ, Manji HK (2003). The use of mood stabilizers as plasticity enhancers in the treatment of neuropsychiatric disorders. J Clin Psychiatr 64(Suppl 5): 3-17.

Griffin LD, Gong W, Verot L, Mellon SH (2004). Niemann-Pick type $\mathrm{C}$ disease involves disrupted neurosteroidogenesis and responds to allopregnanolone. Nat Med 10: 704-711.

Gudemez E, Ozer K, Cunningham B, Siemionow K, Browne E, Siemionow M (2002). Dehydroepiandrosterone as an enhancer of functional recovery following crush injury to rat sciatic nerve. Microsurgery 22: 234-241.

Guo AL, Petraglia F, Criscuolo M, Ficarra G, Nappi RE, Palumbo MA et al (1995). Evidence for a role of neurosteroids in modulation of diurnal changes and acute stress-induced corticosterone secretion in rats. Gynecol Endocrinol 9: 1-7.

Gur RE, Turetsky BI, Cowell PE, Finkelman C, Maany V, Grossman RI et al (2000). Temporolimbic volume reductions in schizophrenia. Arch Gen Psychiatr 57: 769-775.

Hafner H (2003). Gender differences in schizophrenia. Psychoneuroendocrinology 28(Suppl 2): 17-54.

Hakak Y, Walker JR, Li C, Wong WH, Davis KL, Buxbaum JD et al (2001). Genome-wide expression analysis reveals dysregulation of myelination-related genes in chronic schizophrenia. Proc Natl Acad Sci USA 98: 4746-4751.

Halbreich U, Kahn LS (2003). Hormonal aspects of schizophrenias: an overview. Psychoneuroendocrinology 28(Suppl 2): 1-16.

Harrison PJ, Weinberger DR (2005). Schizophrenia genes, gene expression, and neuropathology: on the matter of their convergence. Mol Psychiatr 10: 40-68; image 45.

Haznedar MM, Buchsbaum MS, Hazlett EA, Shihabuddin L, New A, Siever LJ (2004). Cingulate gyrus volume and metabolism in the schizophrenia spectrum. Schizophr Res 71: 249-262.

Hof PR, Haroutunian V, Friedrich Jr VL, Byne W, Buitron C, Perl DP et al (2003). Loss and altered spatial distribution of oligodendrocytes in the superior frontal gyrus in schizophrenia. Biol Psychiatr 53: 1075-1085.

Hu Y, Cardounel A, Gursoy E, Anderson P, Kalimi M (2000). Antistress effects of dehydroepiandrosterone: protection of rats against repeated immobilization stress-induced weight loss, glucocorticoid receptor production, and lipid peroxidation. Biochem Pharmacol 59: 753-762.

Imamura M, Prasad C (1998). Modulation of GABA-gated chloride ion influx in the brain by dehydroepiandrosterone and its metabolites. Biochem Biophys Res Commun 243: 771-775.

Irwin RP, Lin SZ, Rogawski MA, Purdy RH, Paul SM (1994). Steroid potentiation and inhibition of $N$-methyl-D-aspartate receptor-mediated intracellular $\mathrm{Ca}++$ responses: structureactivity studies. J Pharmacol Exp Ther 271: 677-682.

Jarskog LF, Gilmore JH, Selinger ES, Lieberman JA (2000). Cortical bcl-2 protein expression and apoptotic regulation in schizophrenia. Biol Psychiatr 48: 641-650.

Javitt DC (2004). Glutamate as a therapeutic target in psychiatric disorders. Mol Psychiatr 9: 979, 984-997.
Kalimi M, Shafagoj Y, Loria R, Padgett D, Regelson W (1994). Antiglucocorticoid effects of dehydroepiandrosterone (DHEA). Mol Cell Biochem 131: 99-104.

Karavolas HJ, Hodges DR, O’Brien DJ, MacKenzie KM (1979). In vivo uptake of $[3 \mathrm{H}]$ progesterone and $[3 \mathrm{H}] 5$ alpha-dihydroprogesterone by rat brain and pituitary and effects of estradiol and time: tissue concentration of progesterone itself or specific metabolites? Endocrinology 104: 1418-1425.

Karishma KK, Herbert J (2002). Dehydroepiandrosterone (DHEA) stimulates neurogenesis in the hippocampus of the rat, promotes survival of newly formed neurons and prevents corticosteroneinduced suppression. Eur J Neurosci 16: 445-453.

Kennedy N, Boydell J, Kalidindi S, Fearon P, Jones PB, van Os J et al (2005). Gender differences in incidence and age at onset of mania and bipolar disorder over a 35-year period in camberwell, England. Am J Psychiatr 162: 257-262.

Khisti RT, Chopde CT (2000a). Serotonergic agents modulate antidepressant-like effect of the neurosteroid 3alpha-hydroxy5alpha-pregnan-20-one in mice. Brain Res 865: 291-300.

Khisti RT, Chopde CT, Jain SP (2000b). Antidepressant-like effect of the neurosteroid 3alpha-hydroxy-5alpha-pregnan20-one in mice forced swim test. Pharmacol Biochem Behav 67: 137-143.

Kimonides VG, Khatibi NH, Svendsen CN, Sofroniew MV, Herbert J (1998). Dehydroepiandrosterone (DHEA) and DHEA-sulfate (DHEAS) protect hippocampal neurons against excitatory amino acid-induced neurotoxicity. Proc Natl Acad Sci USA 95: 1852 1857.

Kimonides VG, Spillantini MG, Sofroniew MV, Fawcett JW, Herbert J (1999). Dehydroepiandrosterone antagonizes the neurotoxic effects of corticosterone and translocation of stressactivated protein kinase 3 in hippocampal primary cultures. Neuroscience 89: 429-436.

Kimoto T, Tsurugizawa T, Ohta Y, Makino J, Tamura H, Hojo Y et al (2001). Neurosteroid synthesis by cytochrome p450containing systems localized in the rat brain hippocampal neurons: N-methyl-D-aspartate and calcium-dependent synthesis. Endocrinology 142: 3578-3589.

Knable MB, Barci BM, Webster MJ, Meador-Woodruff J, Torrey EF (2004). Molecular abnormalities of the hippocampus in severe psychiatric illness: post-mortem findings from the Stanley Neuropathology Consortium. Mol Psychiatr 9: 544, 609-620.

Koenig HL, Schumacher M, Ferzaz B, Thi AN, Ressouches A, Guennoun $\mathrm{R}$ et al (1995). Progesterone synthesis and myelin formation by Schwann cells. Science 268: 1500-1503.

Kokate TG, Cohen AL, Karp E, Rogawski MA (1996). Neuroactive steroids protect against pilocarpine- and kainic acid-induced limbic seizures and status epilepticus in mice. Neuropharmacology 35: 1049-1056.

Kokate TG, Svensson BE, Rogawski MA (1994). Anticonvulsant activity of neurosteroids: correlation with gamma-aminobutyric acid-evoked chloride current potentiation. J Pharmacol Exp Ther 270: $1223-1229$.

Krystal JH, Karper LP, Seibyl JP, Freeman GK, Delaney R, Bremner JD et al (1994). Subanesthetic effects of the noncompetitive NMDA antagonist, ketamine, in humans. Psychotomimetic, perceptual, cognitive, and neuroendocrine responses. Arch Gen Psychiatr 51: 199-214.

Kurata K, Takebayashi M, Morinobu S, Yamawaki S (2004). betaestradiol, dehydroepiandrosterone, and dehydroepiandrosterone sulfate protect against N-methyl-D-aspartate-induced neurotoxicity in rat hippocampal neurons by different mechanisms. J Pharmacol Exp Ther 311: 237-245.

Lacroix C, Fiet J, Benais JP, Gueux B, Bonete R, Villette JM et al (1987). Simultaneous radioimmunoassay of progesterone, androst-4-enedione, pregnenolone, dehydroepiandrosterone and 17-hydroxyprogesterone in specific regions of human brain. J Steroid Biochem 28: 317-325. 
Lahti AC, Koffel B, LaPorte D, Tamminga CA (1995). Subanesthetic doses of ketamine stimulate psychosis in schizophrenia. Neuropsychopharmacology 13: 9-19.

Lahti AC, Weiler MA, Tamara Michaelidis BA, Parwani A, Tamminga CA (2001). Effects of ketamine in normal and schizophrenic volunteers. Neuropsychopharmacology 25: 455-467.

Lanthier A, Patwardhan VV (1986). Sex steroids and 5-en-3 betahydroxysteroids in specific regions of the human brain and cranial nerves. J Steroid Biochem 25: 445-449.

Laughlin GA, Barrett-Connor E (2000). Sexual dimorphism in the influence of advanced aging on adrenal hormone levels: the Rancho Bernardo Study. J Clin Endocrinol Metab 85: 3561-3568.

Lewis DA, Volk DW, Hashimoto T (2004). Selective alterations in prefrontal cortical GABA neurotransmission in schizophrenia: a novel target for the treatment of working memory dysfunction. Psychopharmacology (Berlin) 174: 143-150.

Majewska MD, Demirgoren S, Spivak CE, London ED (1990). The neurosteroid dehydroepiandrosterone sulfate is an allosteric antagonist of the GABAA receptor. Brain Res 526: 143-146.

Majewska MD, Harrison NL, Schwartz RD, Barker JL, Paul SM (1986). Steroid hormone metabolites are barbiturate-like modulators of the GABA receptor. Science 232: 1004-1007.

Majewska MD, Mienville JM, Vicini S (1988). Neurosteroid pregnenolone sulfate antagonizes electrophysiological responses to GABA in neurons. Neurosci Lett 90: 279-284.

Malhotra AK, Pinals DA, Adler CM, Elman I, Clifton A, Pickar D et al (1997). Ketamine-induced exacerbation of psychotic symptoms and cognitive impairment in neuroleptic-free schizophrenics. Neuropsychopharmacology 17: 141-150.

Marx CE, Trost W, Behm F, Giordano L, Massing M, Rose J (in press). Neuroactive steroids, negative affect, and nicotine dependence in male smokers. Psychopharmacology.

Marx CE, Grobin A, Deutch A, Lieberman J (2005). Atypical Antipsychotics and Stress. In: Steckler T, Kalin N, Reul J (eds). Handbook of Stress and the Brain. Elsevier Science; Amsterdam.

Marx CE, Duncan GE, Gilmore JH, Lieberman JA, Morrow AL (2000a). Olanzapine increases allopregnanolone in the rat cerebral cortex. Biol Psychiatr 47: 1000-1004.

Marx CE, Jarskog LF, Lauder JM, Gilmore JH, Lieberman JA, Morrow AL (2000b). Neurosteroid modulation of embryonic neuronal survival in vitro following anoxia. Brain Res 871: 104-112.

Marx CE, VanDoren MJ, Duncan GE, Lieberman JA, Morrow AL (2003). Olanzapine and clozapine increase the GABAergic neuroactive steroid allopregnanolone in rodents. Neuropsychopharmacology 28: 1-13.

Mathis C, Vogel E, Cagniard B, Criscuolo F, Ungerer A (1996). The neurosteroid pregnenolone sulfate blocks deficits induced by a competitive NMDA antagonist in active avoidance and leverpress learning tasks in mice. Neuropharmacology 35: 1057-1064.

Maurice T, Urani A, Phan VL, Romieu P (2001). The interaction between neuroactive steroids and the sigmal receptor function: behavioral consequences and therapeutic opportunities. Brain Res Brain Res Rev 37: 116-132.

Mayo W, George O, Darbra S, Bouyer JJ, Vallee M, Darnaudery M et al (2003). Individual differences in cognitive aging: implication of pregnenolone sulfate. Prog Neurobiol 71: 43-48.

Mayo W, Lemaire V, Malaterre J, Rodriguez JJ, Cayre M, Stewart MG et al (2005). Pregnenolone sulfate enhances neurogenesis and PSA-NCAM in young and aged hippocampus. Neurobiol Aging 26: 103-114.

Mellon S, Gong W, Griffin LD (2004). Niemann pick type C disease as a model for defects in neurosteroidogenesis. Endocr Res 30: 727-735.

Mendelson JH, Sholar MB, Goletiani N, Siegel AJ, Mello NK (2005). Effects of low- and high-nicotine cigarette smoking on mood states and the HPA axis in men. Neuropsychopharmacology 30: 1751-1763.
Meyer DA, Carta M, Partridge LD, Covey DF, Valenzuela CF (2002). Neurosteroids enhance spontaneous glutamate release in hippocampal neurons. Possible role of metabotropic sigma1-like receptors. J Biol Chem 277: 28725-28732.

Morin C, Zini R, Simon N, Tillement JP (2002). Dehydroepiandrosterone and alpha-estradiol limit the functional alterations of rat brain mitochondria submitted to different experimental stresses. Neuroscience 115: 415-424.

Morrow AL, Devaud LL, Purdy RH, Paul SM (1995). Neuroactive steroid modulators of the stress response. Ann NY Acad Sci 771: 257-272.

Morrow AL, Pace JR, Purdy RH, Paul SM (1990). Characterization of steroid interactions with gamma-aminobutyric acid receptorgated chloride ion channels: evidence for multiple steroid recognition sites. Mol Pharmacol 37: 263-270.

Morrow AL, Suzdak PD, Paul SM (1987). Steroid hormone metabolites potentiate GABA receptor-mediated chloride ion flux with nanomolar potency. Eur J Pharmacol 142: 483-485.

Mtchedlishvili Z, Kapur J (2003). A presynaptic action of the neurosteroid pregnenolone sulfate on GABAergic synaptic transmission. Mol Pharmacol 64: 857-864.

Nagarajan R, Le N, Mahoney H, Araki T, Milbrandt J (2002). Deciphering peripheral nerve myelination by using Schwann cell expression profiling. Proc Natl Acad Sci USA 99: 8998-9003.

Nopoulos P, Flaum M, Andreasen NC (1997). Sex differences in brain morphology in schizophrenia. Am J Psychiatr 154: 1648-1654.

Pallares M, Darnaudery M, Day J, Le Moal M, Mayo W (1998). The neurosteroid pregnenolone sulfate infused into the nucleus basalis increases both acetylcholine release in the frontal cortex or amygdala and spatial memory. Neuroscience 87: 551-558.

Park-Chung M, Malayev A, Purdy RH, Gibbs TT, Farb DH (1999). Sulfated and unsulfated steroids modulate gamma-aminobutyric acid A receptor function through distinct sites. Brain Res 830: 72-87.

Patchev VK, Hassan AH, Holsboer DF, Almeida OF (1996). The neurosteroid tetrahydroprogesterone attenuates the endocrine response to stress and exerts glucocorticoid-like effects on vasopressin gene transcription in the rat hypothalamus. Neuropsychopharmacology 15: 533-540.

Patchev VK, Shoaib M, Holsboer F, Almeida OF (1994). The neurosteroid tetrahydroprogesterone counteracts corticotropinreleasing hormone-induced anxiety and alters the release and gene expression of corticotropin-releasing hormone in the rat hypothalamus. Neuroscience 62: 265-271.

Paul SM, Purdy RH (1992). Neuroactive steroids. FASEB J 6: 23112322.

Pearson Murphy BE, Allison CM (2000). Determination of progesterone and some of its neuroactive ring A-reduced metabolites in human serum. J Steroid Biochem Mol Biol 74: 137-142.

Pierucci-Lagha A, Covault J, Feinn R, Khisti R, Morrow AL, Marx C et al (in press). Subjective effects and changes in steroid hormone concentrations in humans following acute consumption of alcohol. Psychopharmacology.

Pinna G, Costa E, Guidotti A (2004). Fluoxetine and norfluoxetine stereospecifically facilitate pentobarbital sedation by increasing neurosteroids. Proc Natl Acad Sci 101: 6222-6225.

Pinna G, Dong E, Matsumoto K, Costa E, Guidotti A (2003). In socially isolated mice, the reversal of brain allopregnanolone down-regulation mediates the anti-aggressive action of fluoxetine. Proc Natl Acad Sci 100: 2035-2040.

Porcu P, Sogliano C, Cinus M, Purdy RH, Biggio G, Concas A (2003). Nicotine-induced changes in cerebrocortical neuroactive steroids and plasma corticosterone concentrations in the rat. Pharmacol Biochem Behav 74: 683-690.

Prabakaran S, Swatton JE, Ryan MM, Huffaker SJ, Huang JT, Griffin JL et al (2004). Mitochondrial dysfunction in schizo- 
phrenia: evidence for compromised brain metabolism and oxidative stress. Mol Psychiatr 9: 643, 684-697.

Puia G, Santi MR, Vicini S, Pritchett DB, Purdy RH, Paul SM et al (1990). Neurosteroids act on recombinant human GABAA receptors. Neuron 4: 759-765.

Purdy RH, Fitzgerald RL, Alomary AA, Parsons LH (in press). Practical neurochemistry: methods. In: Baker G (ed). Handbook of Neurochemistry and Molecular Neurobiology, 3rd edn, Vol 18. Springer: New York, NY. pp 1-15.

Purdy RH, Moore Jr PH, Rao PN, Hagino N, Yamaguchi T, Schmidt $\mathrm{P}$ et al (1990). Radioimmunoassay of 3 alpha-hydroxy-5 alpha-pregnan-20-one in rat and human plasma. Steroids 55: 290-296.

Purdy RH, Morrow AL, Moore Jr PH, Paul SM (1991). Stressinduced elevations of gamma-aminobutyric acid type A receptor-active steroids in the rat brain. Proc Natl Acad Sci USA 88: 4553-4557.

Raisinghani KH, Dorfman RI, Forchielli E, Gyermek L, Genther G (1968). Uptake of intravenously administered progesterone, pregnanedione and pregnanolone by the rat brain. Acta Endocrinol (Copenhagen) 57: 395-404.

Rasmusson AM, Vasek J, Lipschitz DS, Vojvoda D, Mustone ME, Shi Q et al (2004). An increased capacity for adrenal DHEA release is associated with decreased avoidance and negative mood symptoms in women with PTSD. Neuropsychopharmacology 29: 1546-1557.

Rhodes ME, Li PK, Burke AM, Johnson DA (1997). Enhanced plasma DHEAS, brain acetylcholine and memory mediated by steroid sulfatase inhibition. Brain Res 773: 28-32.

Rhodes ME, Li PK, Flood JF, Johnson DA (1996). Enhancement of hippocampal acetylcholine release by the neurosteroid dehydroepiandrosterone sulfate: an in vivo microdialysis study. Brain Res 733: 284-286.

Romeo E, Cheney DL, Zivkovic I, Costa E, Guidotti A (1994). Mitochondrial diazepam-binding inhibitor receptor complex agonists antagonize dizocilpine amnesia: putative role for allopregnanolone. J Pharmacol Exp Ther 270: 89-96.

Rupprecht R, Holsboer F (1999). Neuroactive steroids: mechanisms of action and neuropsychopharmacological perspectives. Trends Neurosci 22: 410-416.

Seeman MV (2004). Gender differences in the prescribing of antipsychotic drugs. Am J Psychiatr 161: 1324-1333.

Serra M, Littera M, Pisu MG, Muggironi M, Purdy RH, Biggio G (2000). Steroidogenesis in rat brain induced by short- and long-term administration of carbamazepine. Neuropharmacology 39: 2448-2456.

Shu HJ, Eisenman LN, Jinadasa D, Covey DF, Zorumski CF, Mennerick S (2004). Slow actions of neuroactive steroids at GABAA receptors. J Neurosci 24: 6667-6675.

Slewa-Younan S, Gordon E, Harris AW, Haig AR, Brown KJ, FlorHenry $\mathrm{P}$ et al (2004). Sex differences in functional connectivity in first-episode and chronic schizophrenia patients. $A m \mathrm{~J}$ Psychiatr 161: 1595-1602.

Sliwinski A, Monnet FP, Schumacher M, Morin-Surun MP (2004). Pregnenolone sulfate enhances long-term potentiation in CA1 in rat hippocampus slices through the modulation of $N$-methyl-D-aspartate receptors. J Neurosci Res 78: 691-701.

Strous RD, Maayan R, Lapidus R, Stryjer R, Lustig M, Kotler M et al (2003). Dehydroepiandrosterone augmentation in the management of negative, depressive, and anxiety symptoms in schizophrenia. Arch Gen Psychiatr 60: 133-141.

Suzuki M, Wright LS, Marwah P, Lardy HA, Svendsen CN (2004). Mitotic and neurogenic effects of dehydroepiandrosterone (DHEA) on human neural stem cell cultures derived from the fetal cortex. Proc Natl Acad Sci USA 101: 3202-3207.

Szeszko PR, Ardekani BA, Ashtari M, Kumra S, Robinson DG, Sevy $S$ et al (2005). White matter abnormalities in first-episode schizophrenia or schizoaffective disorder: a diffusion tensor imaging study. Am J Psychiatr 162: 602-605.

Szeszko PR, Strous RD, Goldman RS, Ashtari M, Knuth KH, Lieberman JA et al (2002). Neuropsychological correlates of hippocampal volumes in patients experiencing a first episode of schizophrenia. Am J Psychiatr 159: 217-226.

Tamminga CA (1997). Gender and schizophrenia. J Clin Psychiatr 58(Suppl 15): 33-37.

Tkachev D, Mimmack ML, Ryan MM, Wayland M, Freeman T, Jones PB et al (2003). Oligodendrocyte dysfunction in schizophrenia and bipolar disorder. Lancet 362: 798-805.

Torrey EF, Barci BM, Webster MJ, Bartko JJ, Meador-Woodruff JH, Knable MB (2005). Neurochemical markers for schizophrenia, bipolar disorder, and major depression in post-mortem brains. Biol Psychiatr 57: 252-260.

Torrey EF, Webster M, Knable M, Johnston N, Yolken RH (2000). The Stanley Foundation brain collection and neuropathology consortium. Schizophr Res 44: 151-155.

Trost W, Shampine L, Hulette C, Ervin J, Steffens D, Lieberman J et al (2004). Neuroactive steroids in Alzheimer's disease: investigations in prefrontal cortex. In: The American College of Neuropsychopharmacology 43rd Annual Meeting. San Juan, Puerto Rico.

Trost W, Shampine L, Khisti R, Parke G, Morrow A, Lieberman J et al (2005). Olanzapine and fluoxetine effects on hippocampal pregnenolone and peripheral deoxycorticosterone: relevance to therapeutic efficacy. In: International Congress on Schizophrenia Research. Savannah, GA.

Ugale RR, Hirani K, Morelli M, Chopde CT (2004). Role of neuroactive steroid allopregnanolone in antipsychotic-like action of olanzapine in rodents. Neuropsychopharmacology 29: 1597-1609.

Uranova N, Orlovskaya D, Vikhreva O, Zimina I, Kolomeets N, Vostrikov V et al (2001). Electron microscopy of oligodendroglia in severe mental illness. Brain Res Bull 55: 597-610.

Uzunov DP, Cooper TB, Costa E, Guidotti A (1996). Fluoxetineelicited changes in brain neurosteroid content measured by negative ion mass fragmentography. Proc Natl Acad Sci USA 93: 12599-12604.

Uzunova V, Sheline Y, Davis JM, Rasmusson A, Uzunov DP, Costa $\mathrm{E}$ et al (1998). Increase in the cerebrospinal fluid content of neurosteroids in patients with unipolar major depression who are receiving fluoxetine or fluvoxamine. Proc Natl Acad Sci USA 95: 3239-3244.

Vallee M, Mayo W, Darnaudery M, Corpechot C, Young J, Koehl M et al (1997). Neurosteroids: deficient cognitive performance in aged rats depends on low pregnenolone sulfate levels in the hippocampus. Proc Natl Acad Sci USA 94: 14865-14870.

Vallee M, Purdy RH, Mayo W, Koob GF, Le Moal M (2003). Neuroactive steroids: new biomarkers of cognitive aging. $J$ Steroid Biochem Mol Biol 85: 329-335.

Vallee M, Rivera JD, Koob GF, Purdy RH, Fitzgerald RL (2000). Quantification of neurosteroids in rat plasma and brain following swim stress and allopregnanolone administration using negative chemical ionization gas chromatography/mass spectrometry. Anal Biochem 287: 153-166.

Vallee M, Shen W, Heinrichs SC, Zorumski CF, Covey DF, Koob GF et al (2001). Steroid structure and pharmacological properties determine the anti-amnesic effects of pregnenolone sulphate in the passive avoidance task in rats. Eur J Neurosci 14: 2003-2010.

VanDoren MJ, Matthews DB, Janis GC, Grobin AC, Devaud LL, Morrow AL (2000). Neuroactive steroid 3alpha-hydroxy-5alphapregnan-20-one modulates electrophysiological and behavioral actions of ethanol. J Neurosci 20: 1982-1989.

Wang JM, Johnston PB, Ball BG, Brinton RD (2005). The neurosteroid allopregnanolone promotes proliferation of rodent and human neural progenitor cells and regulates cell-cycle gene and protein expression. J Neurosci 25: 4706-4718. 
Wang MD, Wahlstrom G, Backstrom T (1997). The regional brain distribution of the neurosteroids pregnenolone and pregnenolone sulfate following intravenous infusion. J Steroid Biochem Mol Biol 62: 299-306.

Wassef A, Baker J, Kochan LD (2003). GABA and schizophrenia: a review of basic science and clinical studies. J Clin Psychopharmacol 23: 601-640.

Weill-Engerer S, David JP, Sazdovitch V, Liere P, Eychenne B, Pianos A et al (2002). Neurosteroid quantification in human brain regions: comparison between Alzheimer's and nondemented patients. J Clin Endocrinol Metab 87: 5138-5143.

Weill-Engerer S, David JP, Sazdovitch V, Liere P, Schumacher $\mathrm{M}$, Delacourte A et al (2003). In vitro metabolism of dehydro- epiandrosterone (DHEA) to 7alpha-hydroxy-DHEA and Delta5androstene-3beta,17beta-diol in specific regions of the aging brain from Alzheimer's and non-demented patients. Brain Res 969: 117-125.

Wolkowitz OM, Epel ES, Reus VI (2001). Stress hormone-related psychopathology: pathophysiological and treatment implications. World J Biol Psychiatr 2: 115-143.

Wu FS, Gibbs TT, Farb DH (1991). Pregnenolone sulfate: a positive allosteric modulator at the N-methyl-D-aspartate receptor. $\mathrm{Mol}$ Pharmacol 40: 333-336.

Zubieta JK, Huguelet P, Ohl LE, Koeppe RA, Kilbourn MR, Carr JM et al (2000). High vesicular monoamine transporter binding in asymptomatic bipolar I disorder: sex differences and cognitive correlates. Am J Psychiatr 157: 1619-1628. 